Journal of Animal and Veterinary Advances 18 (7): 208-214, 2019

ISSN: 1680-5593

(C) Medwell Journals, 2019

\title{
Comparative Morphological Studies on Testes and Seminal Vesicles of African Catfish (Clarias gariepinus) and Nile Tilapia (Tilapia nilotica)
}

\author{
${ }^{1}$ A. Danmaigoro, ${ }^{2}$ S.A. Hena, ${ }^{1}$ I. Ibrahim, ${ }^{1}$ S. A. Shehu, ${ }^{3}$ M. A. Mahmud, \\ ${ }^{1}$ S.A. Muhammed, ${ }^{4}$ J. Stephen and ${ }^{1}$ A. Bello \\ ${ }^{1}$ Department of Veterinary Anatomy, Usmanu Danfodiyo University, \\ Sokoto PMB 2346, Sokoto, Nigeria \\ ${ }^{2}$ Department of Veterinary Anatomy, University of Jos, \\ Plateau State PMB 2084, Jos, Nigeria \\ ${ }^{3}$ Department of Animal Health and Production Technology, Niger State College of Agriculture, \\ PMB 109, Mokwa, Niger State, Nigeria \\ ${ }^{4}$ Department of Theriogenology and Animal Production, University of Maiduguri, \\ PMB 1069, Borno, Nigeria
}

\begin{abstract}
Comparative morphological studies on the testes and seminal vesicles in African catfish and Nile Tilapia were conducted with the aim of comparing morphological and their architectural differences using anatomical, histological and biometric techniques. A total of the 50 fishes comprising of 25 African catfish and 25 Nile Tilapia fishes were captured and used, their live bodyweights and standard body lengths of the fish were measured using weighing balance in grams $(\mathrm{g})$ and Tape rule in centimeter $(\mathrm{cm})$, respectively. Thereafter, a midline incision was made on the ventral surface of the abdominal column. The positions of the organs were carefully examined in situ with representative samples of each of the testes and the seminal vesicle taken for routine histological evaluations with histomorphometry of the spermatozoa structural index assessment. The findings of this work showed that, the testicular structure and seminal vesicles of both African catfish (Clarias gariepinus) and Nile tilapia (Tilapia nilotica) are morphologically different in sizes, shapes and weight but have some similarities in their colors and locations. The testicular lengths of the African catfish were longer than that of the Nile tilapia $(\mathrm{p}<0.05)$. However, the spermatozoa structural index did not differ statistically even though there was higher is catfish when compared with tilapia with exception of the spermatozoa tail length. Therefore, apart from the contribution of the present study to the knowledge of comparative anatomy in these species of fish, it has equally put forward a baseline data for further comparative studies on the testicular and seminal vesicular morphology in these species.
\end{abstract}

Key words: Morphology, testes, seminal vesicle, African catfish, Nile Tilapia, assessment

\section{INTRODUCTION}

Fish is a limbless vertebrate species that has its gaseous exchange through gills and usually has scaly fins, living wholly in water (Zheng et al., 2016). The African Catfish belongs to the family Claridae (air breathing cat fish), order siluriformes (catfish), class Actinopterygii (ray-finned fishes), sub-phylum Vertebrate, phylum Chordata and kingdom Animalia. The family Claridae is generally divided into two: Clarias and Heterobranchus. There are over 100 species in this family occurring naturally throughout Africa, the Southern half of Asia and the Philipinnes (Gbeddy et al., 2015). Gbeddy et al. (2015) reported that Clariasgariepinus possesses qualities with excellent adaptation features to ambient climate, ability to support high population density under culture condition, disease resistance, high growth rate and very efficient feed conversion ratio, however, with ability to mature and remain gravid throughout the year in captivity and as well as having high consumer acceptance which make it an important aquaculture species. On the other hand, Nile Tilapia (Tilapianilotica) belongs to the family Cichlidae, order Perciformes with the same class, sub-phylum and phylum as well as having their mouth broader as the African cat fish. There are about 2000 species of this family occurring naturally all over the world (Fuentes-Silva et al., 2013). Tilapia culture has been grown over the past decades as an excellent source of high quality protein (Fuentes-Silva et al., 2013). These 2 species of fish are known for their ability to breed and produce new generations rapidly (Fuentes-Silva et al., 2013) and both have high ability to reproduce and remain gravid throughout the year (Maitra and Hasan, 2016).

Corresponding Author: A. Danmaigoro, Department of Veterinary Anatomy, Usmanu Danfodiyo University, Sokoto PM B 2346, Sokoto, Nigeria, Tel:- +234 8037914241 
The male fish has penis, testes and seminal vesicles (milt) but epididymis is absent (Ciereszko et al., 2017; Zakariah et al., 2016a, b). The testes of African catfish (clariids) are situated in the dorsal part of the abdominal cavity (Zakariah et al., 2016a, b). They are lobulated and appeared whitish in colour (Zakariah et al., 2016a, b; Ikpegbu et al., 2012). They are covered by the intestine in such a way that application of pressure cannot easily release semen (Zakariah et al., 2016a, b). As in other fish species, tilapia testes are located in the celomic cavity, dorsal to the digestive tube, ventral to the mesonephrons and ventro-lateral to the swim-bladder (Ikpegbu et al., 2012). The seminiferous tubules in tilapia present a blind pouch located just below the tunica albuginea and is arranged radially in relation to the intratesticular spermatic ductule system (Abdelhamid et al., 2009). These ductules are located in the dorsal aspect of the testes where the spermatic duct is formed (Abdelhamid et al., 2009). The two spermatic ducts (one from each testis) join each other to form the common Spermatic duct that opens in the urogenital papillae (Abdelhamid et al., 2009). Several techniques have been developed by several authors (Woelders and Hiemstra, 2011; Pavlovv, 2006) to preserve fish semen, so as to preserve the genetic quality of valued fish. Experiments were carried out to increase milt volume and to strip milt from male by Melo and Godinho (2018) but with limited success. This is because their reproductive systems have accessory glands, seminal vesicles which empty into the spermatic ducts and secret a viscous fluid comprising a mucopolysaccharide and protein (Cavaco et al., 2001). The seminal vesicles and other internal organs prevent the possible stripping from Clariids and Tilapias males testes (Cavaco et al., 2001). With all the aforementioned importance as well as studies carried out on these 2 fish species, there is still paucity of information on morphological comparison in their testicular and seminal vesicular architectures. Knowledge of comparative morphology on testes and seminal vesicles of these 2 species of fish will add to the available information of high reproductive ability in these fish species. Therefore, this study was carried out with the aim of comparing the morphology of the testes and seminal vesicles of $C$. gariepinus and $T$. nilotica.

\section{MATERIALS AND METHODS}

Twenty-five each, of adult males of C. gariepinus and Tilapia nilotica were obtained from local fishermen in the Sokoto Central Market. The fishes were obtained alive and euthanized by cephalic dislocation, at the Veterinary Anatomy Laboratory, Usmanu Danfodiyo University, Sokoto, Nigeria. The live weights and standard lengths of the fish collected were measured using weighing balance in grams (g) and Tape rule in centimeter (cm) according to the standard procedure described by Castro Silva et al. (2015). On the ventral surface of the column, a midline incision was made on the ventral surface of the abdominal column. The positions of the organs were carefully examined in situ and photographs were taken using a digital camera (Samsung ES 517.5 megapixel). The testis and seminal vesicles were carefully separated out from the cavity. The testicular and seminal vesicular weights and lengths were also measured using tape rule (cm) and weighing balance (g), respectively. Representative samples of testes and seminal vesicle were collected and immediately fixed in Bouin's fluid for $72 \mathrm{~h}$ for routine histology using Haematoxylin and Eosin (H\&E) stains as described by Zakariah et al. (2016a, b). The stained slides were then examined under low and high magnifications of light microscope. Photomicrographs were captured using Amscope 3.7 Version 10 MP camera. G* Power 3.1 Version (HeinrichHeinie-Universitat, Dusseldorf, Germany) was used to calculate the sample size per group of $n=25$ with a priority to the end point of body weight of $210 \mathrm{~g}$ and testicular weight of $3.0 \mathrm{~g}$ with fixed effect size of 0.8 . However, GraphPad PRISM 8.0 (GraphPad Software, Inc, La Jolla, CA) was used to run the Student's T-test. All result obtained were expressed as means with standard deviation for descriptive purpose. A 2-sided $\mathrm{P}$ valve $\mathrm{p}<0.05$ was considered significant.

\section{RESULTS AND DISCUSSION}

Gross morphology: The testes of African catfish (Clarias gariepinus) were observed to be situated in the dorsal part of the abdominal cavity and covered by the intestine. They were lobulated and appeared whitish in colour (Fig. 1). The seminal vesicles were seen to be flattened and fused posteriorly. The external surface of the vesicle was covered by a thin fibrous connective tissue sheath. The seminal vesicle consisted of distinct vesicular lobules of varying shapes and sizes. The seminal vesicles also consisted of 36-44 finger-like lobes made up of tubules in which fluid is secreted. They were located caudal to the testes and also appeared whitish in colour (Fig. 1). The paired testes of the Nile tilapia (Tilapia nilotica) were located in the celomic cavity, dorsally to the digestive tube, ventrally to the mesonephrons and ventro-laterally to the swim-bladder and they were all enclosed bilaterally and ventrally by abdominal walls. They were lobulated and appeared reddish in colour (Fig. 1). The seminal vesicles of the Nile tilapia presented a blind pouch appearance. They were cluster-like, located caudally to the testicles and also reddish in color (Fig. 1).

Gross morphometry: The Average Body Weight (ABW) (g), Standard Body Length (SBL) (cm), Average Testicular Weight (ATW) (g), Mean Testicular Length (MTL) (cm), Mean Seminal Vesicle Weight (MSVW) (g), 
Table 1: Gross Morphometry of Tilapia and Catfish body weights, body lengths, testicular weights, testicular length and seminal vesicular weights

\begin{tabular}{llllll}
\hline Species & BW $(\mathrm{gm})$ & SD $(\mathrm{cm})$ & TW $(\mathrm{gm})$ & TL $(\mathrm{cm})$ & SVW $(\mathrm{gm})$ \\
\hline Tilapia $(\mathrm{n}=25)$ & $157.5 \pm 16.0$ & $20.3 \pm 0.49$ & $0.70 \pm 0.11$ & $4.62 \pm 0.30^{\mathrm{b}}$ & $0.11 \pm 0.01$ \\
Catfish $(\mathrm{n}=25)$ & $211.1 \pm 10.8$ & $24.3 \pm 0.61$ & $2.03 \pm 0.17$ & $5.40 \pm 0.50^{\mathrm{a}}$ & $1.43 \pm 0.05$ \\
\hline
\end{tabular}

Table 2: Relative testicular weight index and relative seminal vesicular weight index of both Catfish and Tilapia

\begin{tabular}{lcc}
\hline Species & Relative testicular weight index (\%) & Relative seminal vesicular weight index (\%) \\
\hline Catfish $(\mathrm{n}=25)$ & 0.96 & 0.67 \\
Tilapia $(\mathrm{n}=25)$ & 0.44 & 0.06 \\
\hline
\end{tabular}
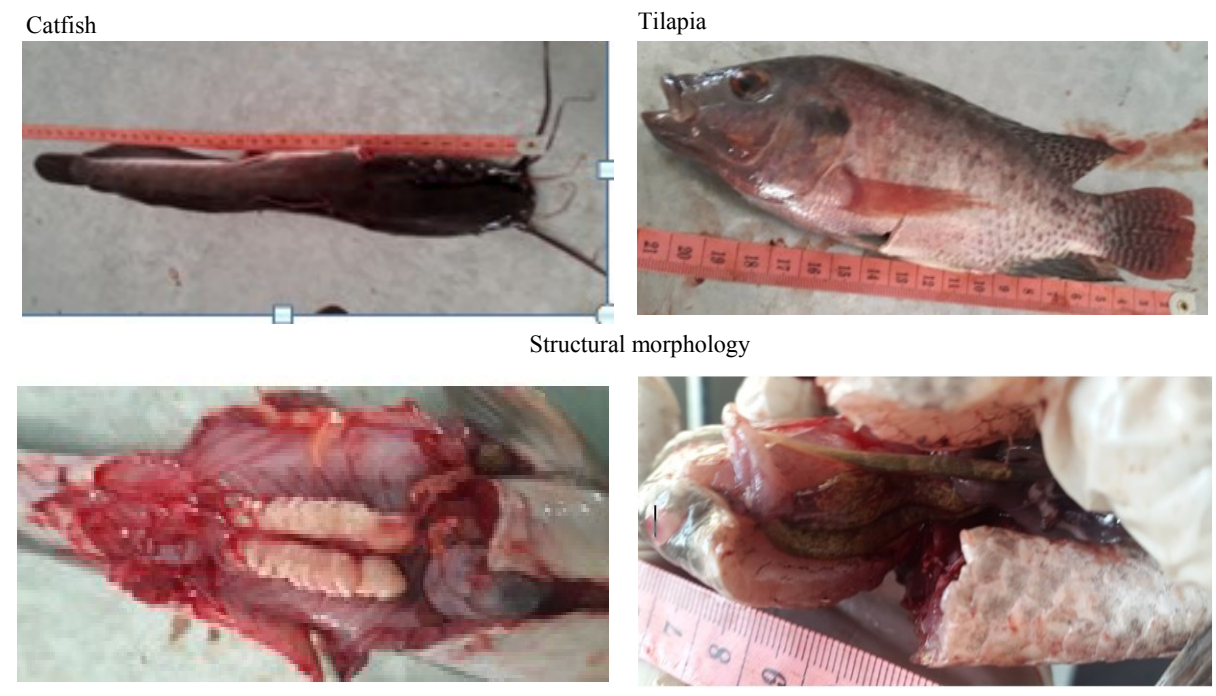

Testicular and seminal vesicles structural relation in situ
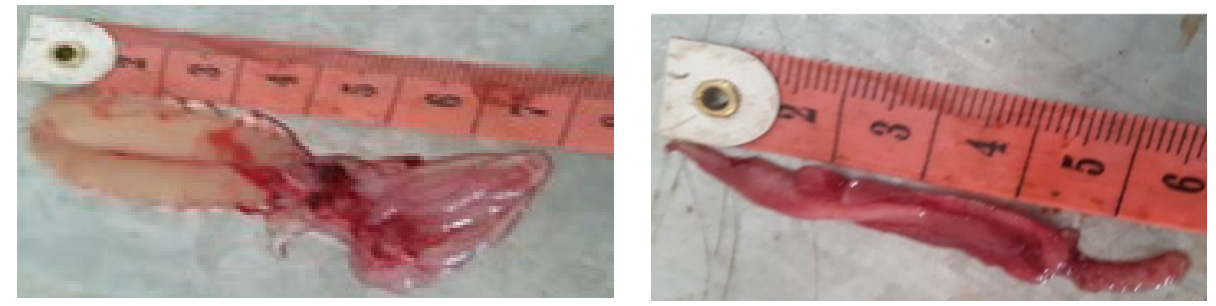

Testis and seminal vesicle excised

Fig. 1: African Catfish and Nile Tilapia fish with their Testicular (T) and Seminal Vesicles (SV) showing their morphological relationship in situ in the coelom

Average Relative Testicular Index (ARTI) and Average Seminal Vesicular Index (ASVI) of Catfish were $211.10 \pm 10.80 \mathrm{~g}, 24.30 \pm 0.61 \mathrm{~cm}, 2.03 \pm 0.17 \mathrm{~g}$, $5.40 \pm 0.50 \mathrm{~cm}, 1.43 \pm 0.05 \mathrm{gm}, 0.96$ and $0.67 \%$, respectively (Table 1 and 2). In Tilapia the ABW (g), SBL (cm), ATW (g), MTL (cm), MSVW (g), ARTI and ASVI were $157.50 \pm 16.0 \mathrm{~g}, 20.30 \pm 0.49 \mathrm{~cm}, 0.70 \pm 0.11 \mathrm{~g}$, $4.62 \pm 0.30 \mathrm{~cm}, 0.11 \pm 0.01 \mathrm{~g}, 0.44$ and $0.06 \%$, respectively (Table 1 and 2). The MTL of the African catfish significantly longer $(p<0.05)$ than that of the Nile tilapia fish.
Histomorphology: Histomorphologically, the testes of both African catfish and Nile tilapia, showed tunica albuginea of loose connective tissues and the spermatic duct. The duct contained sperm cells, surrounded by connective tissue which separates the numerous branches of the tubules that connect to the apical tubular region of the testicules. The interstitial cells of Leydig were within the secretory interstitial tissues (Fig. 2 and 3). The Leydig cells were polygonal in shape with ill-defined cell boundaries and had centrally located spherical nuclei. The histology of seminal vesicles of both species showed 


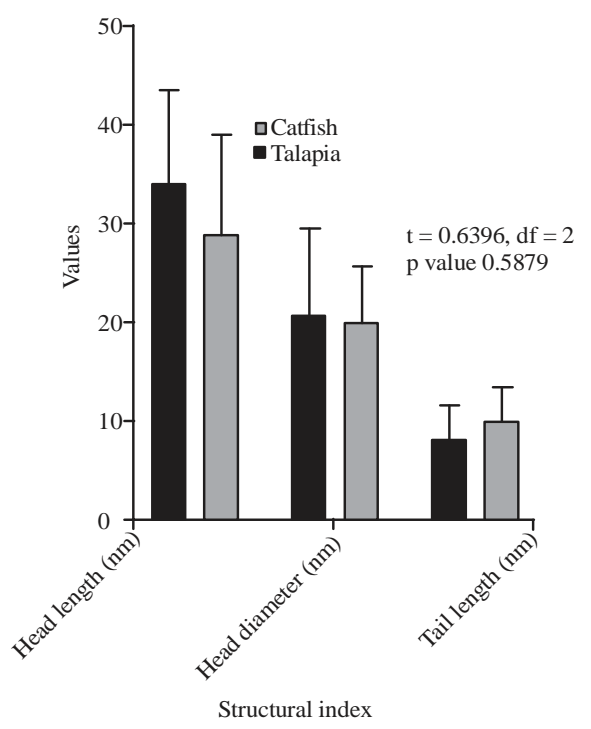

Fig. 2: Histomorphometry of some spermatozoa structural index of both Catfish and Tilapia
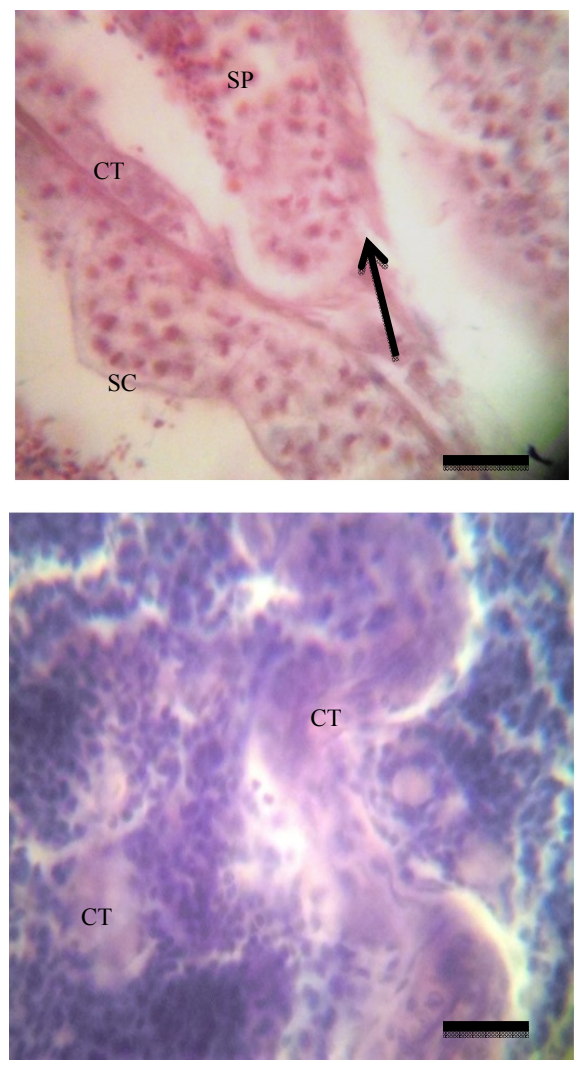

spresence of the vesicular fluid, covering capsule of vesicular connective tissue, secretory cells and spermatogenic cells (Fig. 3 and 4).

The spermatozoa structural index such as head length, head diameter and tail length of the catfish were higher than that of the tilapia fish with exception of the tail length which is low in catfish than tilapia, although, of the index is statistical significant went subjected to student $\mathrm{t}$ test with a p value of $0.5879, \mathrm{t}=0.6396, \mathrm{df}=2$ as show in Fig. 2-4.

Gross morphology and gross morphometry: The gross structure of the paired testes of both species found to be situated in the dorsal part of the abdominal cavity and covered by the intestine is similar to the report of (Orlu and Ogbalu, 2011) who reported that, the gross structure of the testes of the African catfish showed paired elongated lobes with the caudal region presenting ostentatious seminal vesicles, in contrast to other species. The digit form projections or fringes seen communicating with the spermatic duct, observed in this present
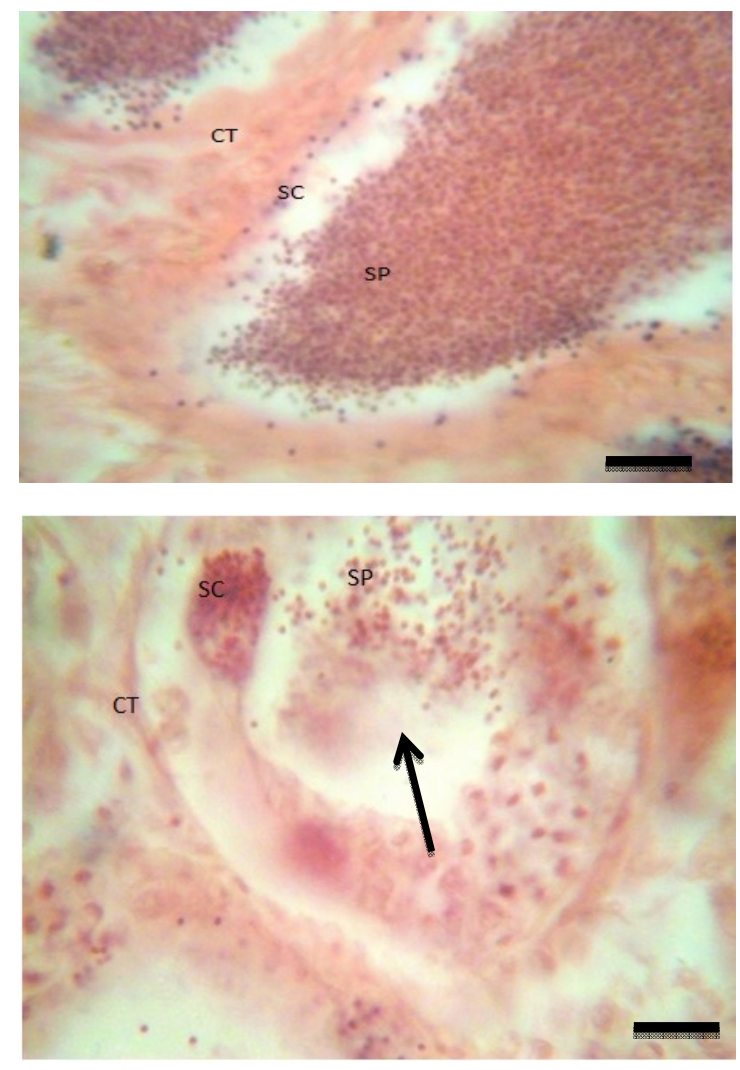

Fig. 3: Photomicrograph of both transverse section of testicles and seminal vesicle of catfish and tilapia fish showing the covering capsule of loose Connective Tissue (CT), Secretory Cells (SC) and Spermatogenic Cells (SP) and seminal vesicle tubules lumen filled with secretions (arrow) H\&E (bar $=100 \mu \mathrm{m})$ 

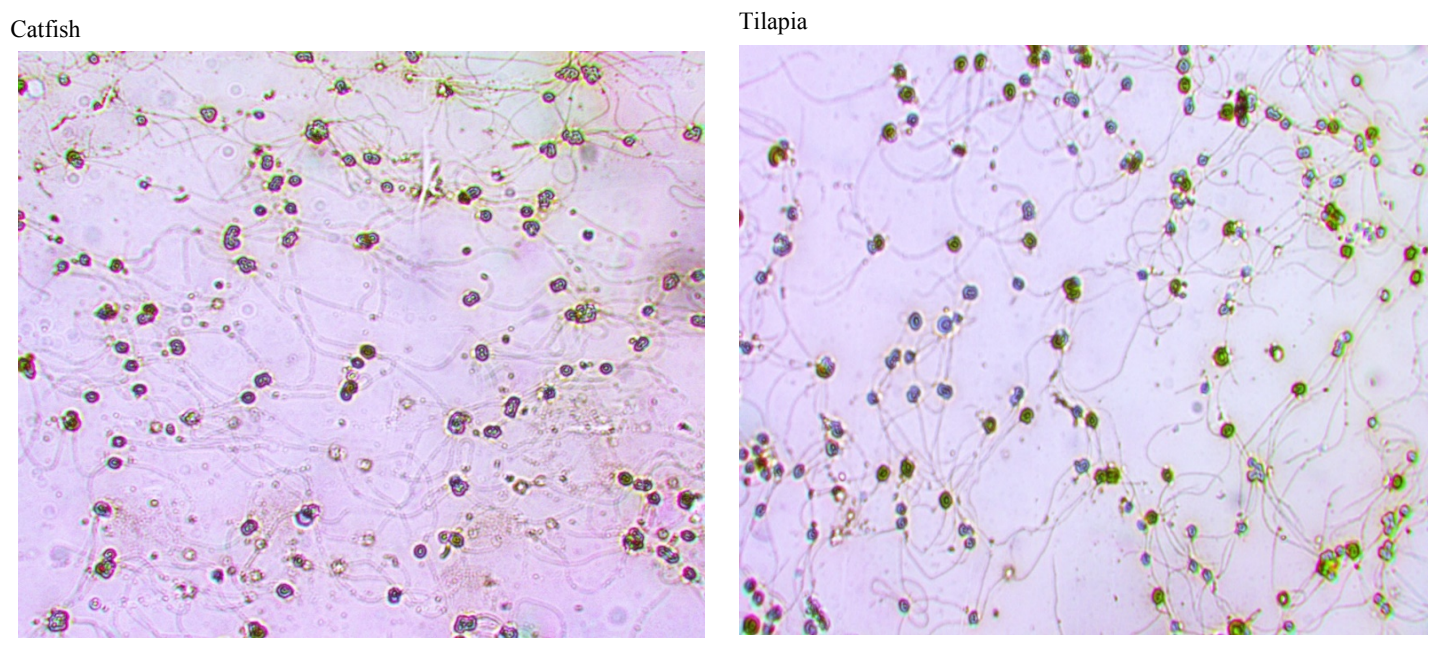

Fig. 4: Photomicrograph of spermatozoa structural index of both catfish and Tilapia showing the spermatozoa head length, spermatozoa head diameter and spermatozoa tail

study were also reported in several Siluriformis groups (Lopes et al., 2004). The results on seminal vesicles of Clarias gariepinus observed in the current study indicates that the vesicle have finger-like lobes built up of lobules which were located caudal to the testes, this is in agreement with the observations made by Zakariah et al. (2016a, b) on the seminal vesicles of the African catfish (Clarias gariepinus).

The present finding with respect to the location of the paired testes in both species were similar to the earlier reports of Zakariah et al. (2016a, b). They reported that the bilateral testes of Nile fish were suspended from the dorsal portion of the body cavity, ventral to the kidneys. The location and portion of the seminal vesicles observed in this present study were similar to the report of Mazzoldi et al. (2007) and Spadella et al. (2017) in Callichthyidae family with the secretory activity occurring in the caudal portion with or without the seminal vesicles. Also in the families of Heteroneustidae, Clariidae and Auchenipteridae seminal vesicles occur in the caudal region of the reproductive system, as reported by Meisner et al. (2000).

Histomorphology: The testes of both African catfish and Nile tilapia, observed in this present study to have tunica albuginea of loose connective tissues and the spermatic duct containing sperm cells, surrounded by connective tissue are in agreement with the earlier studies of Awaad et al. (2014) in Nile tilapia and the pattern observed in most teleosts (Carlos and Matta, 2009). The African catfish and Nile tilapia, share the basic structures with other fishes (Meisner et al., 2000), avian (Friedlander and Parrish, 1997) and mammalian species (Ahmed et al., 2013). The seminal vesicles of both
African catfish Nile tilapia observed in this current study have the vesicular fluid, the vesicular connective tissue is in contrast to the report of Ahmed et al. (2013) in Clairias species who reported the absent of the seminal vesicles altogether within the caudal portion.

This result of the current study which revealed that, the interstitial cells of Leydig which were present in the intertubular spaces with numerous blood capillaries in both species is similar to the reports of Wepener et al. (2001) in Tilapia randalii (Arnold et al., 2000) in Oreochromis niloticus (Nakaghi et al., 2003) in Colossoma macropomum and (Smita et al., 2005) in Ichthyophis tricolor. The results of the present study on Leydig cells being polygonal in shape with ill-definite cell boundaries and centrally located spherical nuclei are in line with the result of Zakariah et al. (2016a, b) and El-Sakhawy et al. (2011) in Clarias gariepinus (Ahmed et al., 2013) in Clarias microcephalus, in Oreochromis niloticus. The results of the present study on the histology of the seminal vesicles of both African catfish and Nile tilapia have the vesicular connective tissue, the vesicular fluid and the interstitial secretory cells which are similar to the previous reports of (Van den Hurk et al., 1987) in these species.

\section{CONCLUSION}

This research has shown that, the testicular structure and seminal vesicular structure of African catfish (Clarias gariepinus) and that of Nile tilapia (Tilapia nilotica) vary morphologically in their sizes, shapes and weights but have some similarities in their colors and locations. Therefore, apart from the contribution of the present study to the knowledge of comparative anatomy in these species 
of fish, it has equally put forward a baseline data for further comparative studies on the testicular and seminal vesicular morphology in these species. It is therefore, recommended to evaluate the course of the differences which might be responsible for the different reproductive performance.

\section{ACKNOWLEDGEMENTS}

This study was partly supported by Department of the Veterinary Anatomy, Faculty of Veterinary Medicine, Usmanu Danfodiyo University, Sokoto-Nigeria by providing histological reagents and equipment. The authors thank Prof. Dr. Abdel-Hemid Kamel Osman of the Department of Cytology and Histology, Suez Canal University Ismailia, Egypt for critically reviewing the manuscripts. Thanks also to Mr. Jimoh Mustapha for his technical assistance in the dissection and histological tissue processing.

\section{REFERENCES}

Abdelhamid, A.M., A.I. Mehrim, M.F.I. Salem and H.A.E. Yosuf, 2009. All-male monosex Nile Tilapia (Oreochromis niloticus), pros and cons. Egypt. J. Basic Applied Physiol., 8: 41-57.

Ahmed, Y.A., N.A.A. Samei and A.Z. Zayed, 2013. Morphological and histomorphological structure of testes of the catfish clarias gariepinus from Egypt. Pak. J. Biol. Sci., 16: 624-629.

Awaad, A.S., U.K. Moawad and M.G. Tawfiek, 2014. Comparative histomorphological and histochemical studies on the oesophagus of nile tilapia oreochromis niloticus and african catfish clarias gariepinus. J. Histol., 10.1155/2014/987041

Carlos, J. and S.L.P.D. Matta, 2009. Microscopic morphology and testis morphometry of captivity-bred Adult bullfrogs (Lithobates catesbeianus Shaw, 1802). Braz. Arch. Biol. Technol., 52: 1461-1472.

Cavaco, J.E.B., J. Bogerd, H. Goos and R.W. Schulz, 2001 . Testosterone in hibits 11-ketotestosterone-induced spermatogenesis in African catfish (Clarias gariepinus). Biol. Reprod., 65: 1807-1812.

Ciereszko, A., M.A. Dietrich and J. Nynca, 2017. Fish semen proteomics-new opportunities in fish reproductive research. Aquaculture, 472: 81-92.

El-Sakhawy, M.A., A.A. El-Saba, M.I. Abd Rabou, M.A. El-Shammaa and S.H. Hussein, 2011. Seasonal histology of the testes of Nile tilapia (Oreochromis niloticus). J. Vet. Anatomy, 4: 61-75.

Friedlander, A.M. and J.D. Parrish, 1997. Fisheries harvest and standing stock in a Hawaiian Bay. Fish. Res., 32: 33-50.
Fuentes-Silva, C., G.M. Soto-Zarazua, I. Torres-Pacheco and A. Flores-Rangel, 2013. Male tilapia production techniques: A mini-review. Afr. J. Biotechnol., 12: 5496-5502.

Gbeddy, G., E. Glover, I. Doyi, S. Frimpong and L. Doamekpor, 2015. Assessment of organochlorine pesticides in water, sediment, African cat fish and Nile tilapia, consumer exposure and human health implications, Volta Lake. Ghana. J. Environ. Anal. Toxicol., Vol. 5, No. 4. 10.4172/2161-0525.1000297

Ikpegbu, E., U.C. Nlebedum, O. Nnadozie and I.O. Agbakwuru, 2012. The testis and seminal vesicle of the farmed male African Catfish: A histological and mucin histochemical observation. J. Agric. Vet. Sci., 1: 37-40.

Lopes, D.C.J.R., N. Bazzoli, M.F.G. Brito and T.A. Maria, 2004. Male reproductive system in the South American catfish Conorhynchus conirostris. J. Fish Biol., 64: 1419-1424.

Maitra, S.K. and K.N. Hasan, 2016. The role of melatonin as a hormone and an antioxidant in the control of fish reproduction. Front. Endocrinol., Vol. 7, 10.3389/fendo.2016.00038

Mazzoldi, C., V. Lorenzi and M.B. Rasotto, 2007. Variation of male reproductive apparatus in relation to fertilization modalities in the catfish families Auchenipteridae and Callichthyidae (Teleostei: Siluriformes). J. Fish Biol., 70: 243-256.

Meisner, A.D., J.R. Burns, S.H. Weitzman and L.R. Malabarba, 2000. Morphology and histology of the male reproductive system in two species of internally inseminating South American catfishes Trachelyopterus lucenai and T. galeatus (Teleostei: Auchenipteridae). J. Morphol., 246: 313-342.

Melo, F.C.S.A. and H.P. Godinho, 2018. A protocol for cryopreservation of spermatozoa of the fish Brycon orthotaenia. Anim. Reprod. (AR.), 3: 380-385.

Nakaghi, L.S.O., D. Mitsuiki, H.S.L. Santos, M.R. Pacheco and L.N. Ganeco, 2003. Morphometry and morphology of nucleus of the Sertoli and interstitial cells of the tambaqui Colossoma macropomum (Cuvier, 1881) (Pisces: Characidae) during the reproductive cycle. Braz. J. Biol., 63: 97-104.

Orlu, E.E. and O.K. Ogbalu, 2011. Effect of sublethal concentrations of Lepidagathis alopecuroides (Vahl) on sperm quality, fertility and hatchability in gravid Clarias gariepinus (Burchell, 1822) broodstock. Res. J. Environ. Toxicol., 5: 117-124.

Pavlov, D.A., 2006. A method for the assessment of sperm quality in fish. J. Ichthyol., Vol. 46, 10.1134/S0032945206050055

Silva, T.S.D.C., L.D.D. Santos, L.C.R.D. Silva, M. Michelato and V.R.B. Furuya et al., 2015. Length-weight relationship and prediction equations of body composition for growing-finishing cage-farmed Nile tilapia. Rev. Bras. de Zootecnia, 44: 133-137. 
Smita, M., R.S. Beyo, J.M. George, M.A. Akbarsha and O.V. Oommen, 2005. Seasonal variation in spermatogenic and androgenic activities in a caecilian testis (Ichthyophis tricolor). J. Zool., 267: 45-53.

Spadella, M.A., S.P. Desan, T.C. Henriques and C. Oliveira, 2017. Variation in male reproductive system characters in Corydoradinae (Loricarioidei: Callichthyidae) reflects the occurrence of different lineages in this subfamily. Neotrop. Ichthyol., Vol. 15, 10.1590/1982-0224-20160039

Van den Hurk, R., J.W. Resink and J. Peute, 1987. The seminal vesicle of the African catfish, Clarias gariepinus: A histological, histochemical, enzyme-histochemical ultrastructural and physiological study. Cell Tissue Res., 247: 573-582.

Wepener, V., J.H.J. Van Vuren and H.H. Du Preez, 2004. Uptake and distribution of a copper, iron and zinc mixture in gill, liver and plasma of a freshwater teleost, Tilapia sparrmanii. Water SA, 27: 99-108.
Woelders, H. and S.J. Hiemstra, 2011. The potential of cryopreservation and reproductive technologies for animal genetic resources conservation strategies. Cryobiology, 63: 316-317.

Zakariah, M., A. Yahaya, M.L. Sonfada and I. Wiam, 2016a. Male organs of African catfish (Clarias gariepinus) in spawning and non-spawning periods in Maiduguri, Borno State, Nigeria. Sokoto J. Vet. Sci., 14: 34-38.

Zakariah, M., B.G. Gambo, I.D. Peter, Y.A. Gazali and J. Stephen, 2016b. Anatomical studies of the testes of wild African catfish (Clarias gariepinus) in spawning and non-spawning seasons in Maiduguri, Nigeria. Int. J. Fish. Aquat. Stud., 4: 272-277.

Zheng, H., W. Ji, G.R. Zhang, X.T. Zhang and Z.C. Shi et al., 2016. Molecular characterization and expression analyses of the complement component C8a, C8ß and C9 genes in yellow catfish (Pelteobagrus fulvidraco) after the Aeromonas hydrophila challenge. Int J. Mol. Sci., Vol. 17, No. 3. 10.3390/ijms17030345. 